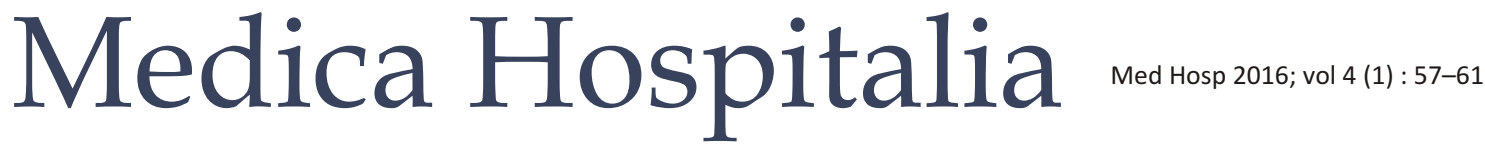

Original Article

\section{Pengaruh Hipnotherapi Terhadap Penurunan Tingkat Nyeri dan Kecemasan Pada Pasien Kemoterapi di RS Dr. Kariadi}

\author{
Anna Jumatul Laely
}

Perawat RSUP Dr. Kariadi Semarang

\begin{abstract}
Abstrak
Latar belakang : Salah satu standar pelayanan yang disebutkan dalam akreditasi rumah sakit adalah bahwa rumah sakit harus mampu memberikan pelayanan dalam pengelolaan rasa nyeri secara efektif terhadap pasien. Pengelolaan rasa nyeri pasien merupakan tanggung jawab tim yang memberikan perawatan terhadap pasien, termasuk di dalamnya adalah perawat. Kanker merupakan salah satu penyakit yang berhubungan dengan rasa nyeri dan kecemasan pasien. Berdasarkan studi awal pasien kanker yang menjalani kemoterapi akan mengeluhkan rasa nyeri dan juga timbul gangguan psikologis berupa kecemasan. Hipnoterapi merupakan metode terapi non farmakologis untuk mengurangi nyeri dan kecemasan pasien yang sedang menjalani kemoterapi Penelitian ini bertujuan untuk mengetahui pengaruh hipnoterapi terhadap penurunan tingkat nyeri dan kecemasan pada pasien kemoterapi di RSUP Dr. Kariadi Semarang.

Metode : Penelitian trial dengan pre-test and post-test design. Pada penelitian ini trial atau intervensi hipnoterapi hanya dilakukan satu kali terhadap subyek. Sampel yang digunakan sejumlah 30 responden yang sedang menjalani kemoterapi. Sampel diambil secara purposive sampling. Instrumen untuk mengukur tingkat nyeri adalah VAS (Visual Analog Scale) dan hypnosis dilakukan dengan memberikan music untuk relaksasi dan pemberian sugesti pada pasien.

Hasil : menunjukkan tingkat nyeri dan kecemasan pasien yang sedang menjalani kemoterapi lebih cenderung pada tingkat sedang dan berat. Terjadi penurunan yang signifikan terhadap tingkat nyeri dan kecemasan pasien kemoterapi setelah dilakukannya hipnoterapi. Skala rata-rata tingkat nyeri sebelum diberikan hipnoterapi yaitu 5,1 dengan skala nyeri terbesar pada angka 9, sesudah dilakukan hypnoterapi skala nyeri rata-rata menjadi 3,5 dengan skala terendah pada angka 1 . Skala rata-rata tingkat kecemasan pasien kemoterapi sebelum diberikan hipnoterapi yaitu 61,67 dengan skala terbesar pada angka 90, sesudah dilakukan hypnoterapi skala tingkat kecemasan rata-rata 36,33 dengan skala penurunan sampai dengan angka 20. Berdasarkan hasil uji Wilcoxon sign rank test menunjukkan ada pengaruh yang signifikan hypnoterapi terhadap penurunan
\end{abstract}

\section{The effect of hypnotherapy to declining rate of pain and anxiety patient with chemotherapy in Dr. kariadi hospital}

\begin{abstract}
Background: One of the standard of service described in hospital accreditation is that hospitals should be able to provide services in managing pain effectively to patients. Pain Management of patient was the responsibility of the team that provides care to patients, including the nurses. Cancer is one of the diseases associated with pain and anxiety of patients. Based on a preliminary study of cancer patients undergoing chemotherapy will complain of pain and psychological disorders such as anxiety arises. Hypnotherapy is a method of non-pharmacological therapies to reduce pain and anxiety of patients undergoing chemotherapy. This research to determine the effect of hypnotherapy on reduction of pain and anxiety in patients with chemotherapy in Doctor Kariadi Hospital Semarang.

Methods : Trial research with pre-test and post-test design. In this research trial or intervention of hypnotherapy was performed only once against subject. The sample used a total of 30 respondents who are undergoing chemotherapy. Samples were taken by purposive sampling. Instruments to measure the level of pain was VAS (Visual Analog Scale) and hypnosis is done by providing music for relaxation and giving suggestions to the patient.

Results : The results showed the level of pain and anxiety of patients undergoing chemotherapy are more likely to moderate and severe. Significant decrease in the level of pain and anxiety of patients with chemotherapy after doing hypnotherapy. The scale of the average level of pain before being given hypnotherapy is 5.1 with the greatest pain scale at number 9 , after done hypnoterapi average pain scale to 3.5 with the lowest scale at 1 . The scale of the average level of anxiety patients given chemotherapy before hypnotherapy is 61.67 with the greatest scale at number 90 , after done hypnoterapi scale anxiety levels on average 36.33 with a
\end{abstract}


tingkat nyeri $(p$ value $=0.00)$ dan tingkat kecemasan $(p$ value $=$ 0.00).

Simpulan : Berdasarkan hasil penelitian ini diharapkan rumah sakit dapat menjadikan metode hipnoterapi sebagai salah satu panduan pelayanan untuk pengelolaan nyeri dan kecemasan pada pasien dan juga metode ini dapat dikembangkan sebagai salah satu standar operasional asuhan keperawatan paliatif care, sehingga bisa meningkatkan kualitas pelayanan.

Kata Kunci : Hipnoterapi, Nyeri, Cemas, Kemoterapi.

\section{PENDAHULUAN}

Salah satu standar penilaian akreditasi rumah sakit guna peningkatan mutu pelayanan adalah bagaimana rumah sakit memberikan pelayanan terhadap pengelolaan rasa nyeri pasien. Rasa nyeri merupakan permasalahan paling umum yang dikeluhkan para pasien kanker dengan kemoterapi, tingkat nyeri ini akan diperberat dengan adanya gangguan psikologis dengan munculnya rasa cemas yang dialami oleh pasien. Intervensi asuhan keperawatan yang dapat dilakukan untuk mengatasi nyeri dan kecemasan pada pasien, melalui tindakan kolaboratif dan tindakan mandiri keperawatan. Tindakan mandiri yang dapat dilakukan oleh seorang perawat dalam pengelolaan nyeri dan cemas pasien adalah dengan cara manajemen nyeri melalui relaksasi, guided imagery, terapi musik, distraksi, hypnosis dan lainlain (Mc. Closkey dan Bulecheck, 2000). Berdasarkan beberapa penelitian hipnoterapi terbukti mampu membuat dan merangsang kekuatan pikiran ke tingkat potensial teroptimalnya dalam menyembuhkan tubuh dan membebaskannya dari penyakit, termasuk mengurangi atau membebaskan rasa nyeri dan kecemasan. Pikiran setiap orang terbukti dapat membuat kondisi kesehatannya membaik atau memburuk, tergantung kepada kekuatan pikir seseorang berikut intervensi medis yang telah diterapkan dokter untuk mewujudkan tujuan sembuhnya (Hipnoterapis Klinis/Medis, http://sites.google.com/site/ untunghypnotherapy). Metode hypnosis atau biasa disebut hipnoterapi, dapat dilakukan oleh semua orang termasuk perawat. Keuntungan hipnoterapi yang lain adalah murah, mudah, tanpa efek samping, dan holistic approach.

Dari beberapa alasan diatas, maka peneliti tertarik untuk melakukan penelitian tentang Adakah Pengaruh Hypnoterapi Relaksasi terhadap Penurunan Tingkat Nyeri dan Kecemasan pada Pasien yang mendapatkan Kemoterapi. Tujuan penelitian adalah untuk mengetahui pengaruh hypnoterapi relaksasi dalam pengelolaan nyeri dan kecemasan pada pasien kemoterapi. Sedangkan tujuan khususnya adalah untuk mengidentifikasikan faktor yang mempengaruhi nyeri dan kecemasan pada pasien yang menjalani kemoterapi, mengidentifikasi tingkat nyeri dan kecemasan pasien kemoterapi dan scale the lowest scale at 20. Based on the test results of Wilcoxon signed rank test showed significant effect hypnoterapi to decrease pain levels ( $p$ value $=0.00$ ) and anxiety level $(p$ value $=0.00)$.

Conclusion : Based on the results of this study are expected the hospital using methods of hypnotherapy as a service guide for the management of pain and anxiety in patients and also this method can be developed as one of the operational standards of nursing care of palliative care, so that it can improve the quality of care.

Keywords : Hipnoterapi, Pain, Anxiety, Chemotherapy.

menganalisis pengaruh hipnoterapi terhadap tingkat nyeri dan kecemasannya tersebut.

\section{METODE}

Desain penelitian adalah penelitian dengan menggunakan pretest-post test design. Pada penelitian ini trial atau intervensi hipnoterapi hanya dilakukan satu kali terhadap subyek. Tehnik sampling yang digunakan peneliti adalah purposive sampling berdasarkan kriteria inklusi pasien dewasa berumur 18-70 tahun, mempunyai daya fokus dan sugestifitas yang tinggi, tidak ada gangguan pendengaran dan penglihatan, tidak ada kelainan jiwa. Jumlah sampel dalam penelitian ini adalah 30 orang dengan kasus kanker yang sedang menjalani kemoterapi di RSUP Dr. Kariadi Semarang . Penelitian dilakukan pada periodeOktober-Desember 2012.

Instrumen penelitian yang digunakan untuk menilai tingkat nyeri dan kecemasan peneliti akan menggunakan Visual Analog Scale (VAS) yang didasarkan pada Numeric Pain Distress scale untuk tingkat nyeri dan Numeric Rating Scale untuk tingkat kecemasan. Untuk proses hipnoterapi, peneliti bertindak sebagai terapis dengan menggunakan pendulum sebagai alat bantu.

Analisa yang digunakan yaitu analisa univariat dan analisa bivariat. Analisa univariat mendiskripsikan data tingkat nyeri dan kecemasan pasien sebelum dan sesudah dilakukannya intervensi. Sedangkan analisa bivariat menganalisa pengaruh hypnoterapi pada pasien kemoterapi. Penelitian telah mendapatkan persetujuan dari komisi etik penelitian kesehatan fakultas kedokteran UNDIP No.394/EC/FK/RSDK/2012.

\section{HASIL}

Berdasarkan tabel 1, usia terbanyak dari responden adalah usia dewasa pertengahan dengan jenis kelamin terbanyak adalah perempuan. Latar belakang pendidikan terbesar dari responden adalah sarjana pekerjaan sebagai pegawai atau pensiunan. Sebagian besar responden masih berstatus menikah dan sedang menjalani kemoterapi dengan siklus yang bervariatif.

Berdasarkan tabel 2 nyeri terbesar yang dirasakan oleh pasien kemoterapi adalah nyeri sedang dengan prosentase $66,7 \%$. 


\begin{tabular}{|c|c|c|}
\hline \multicolumn{3}{|c|}{$\begin{array}{l}\text { Karakteristik Responden Pasien Kanker } \\
\text { Dengan Kemoterapi di RSUP Dr. Kariadi Semarang } \\
\text { bulan November-Desember } 2012(n=30)\end{array}$} \\
\hline Karakteristik & Jumlah & Prosentase \\
\hline \multicolumn{3}{|l|}{ Usia (tahun) } \\
\hline $18-40$ & 1 & 3,3 \\
\hline $41-60$ & 23 & 76,7 \\
\hline $61-70$ & 6 & 20 \\
\hline \multicolumn{3}{|l|}{ Jenis kelamin } \\
\hline Perempuan & 25 & 83,3 \\
\hline Laki-laki & 5 & 16,7 \\
\hline \multicolumn{3}{|l|}{ Pendidikan } \\
\hline SD & 3 & 10 \\
\hline SMP & 3 & 10 \\
\hline SMA & 11 & 36,7 \\
\hline Sarjana & 13 & 43,3 \\
\hline \multicolumn{3}{|l|}{ Pekerjaan } \\
\hline Pegawai & 15 & 50 \\
\hline Wiraswasta & 3 & 10 \\
\hline Tdk Bekerja/Pensiunan & 12 & 40 \\
\hline \multicolumn{3}{|l|}{ Status Perkawinan } \\
\hline Menikah & 28 & 93,3 \\
\hline Janda/duda & 2 & 6,7 \\
\hline Cerai & 0 & 0 \\
\hline \multicolumn{3}{|l|}{ Kemoterapi yang ke } \\
\hline $1-3$ & 10 & 33,3 \\
\hline $4-6$ & 16 & 53,3 \\
\hline $7-9$ & 4 & 13,4 \\
\hline
\end{tabular}

Berdasarkan tabel 3 terjadi penurunan nyeri yang signifikan oleh pasien kemoterapi setelah perlakuan hipnoterapi yaitu sebesar $56,7 \%$ sudah berada pada nyeri ringan.

Berdasarkan tabel 4 cemas terbesar yang dirasakan oleh pasien kemoterapi adalah cemas sedang dengan prosentase 73,3\% . Skala cemas terendah sebelum perlakuan adalah 40 dan skala cemas terbesar adalah 90 .

Tabel 5 menunjukkan bahwa cemas yang dirasakan oleh pasien kemoterapi setelah dilakukan perlakuan adalah terjadi penurunan kecemasan pasien menuju cemas ringan sebanyak $76,7 \%$ dan tidak ada lagi pasien yang mengalami cemas berat.

Uji Wilcoxon sign rank test menunjukkan $p$ value $=$ $0.00<0.05$, yang berarti bahwa ada pengaruh yang signifikan hypnoterapi terhadap penurunan tingkat nyeri dan kecemasan.

\begin{tabular}{|c|c|c|c|}
\hline \multicolumn{4}{|c|}{$\begin{array}{l}\text { TABEk } 2 \\
\text { Tingkat nyeri pasien kemoterapi } \\
\text { di RSUP Dr Kariadi Semarang sebelum } \\
\text { dilakukannya Hypnoterapi }\end{array}$} \\
\hline Tingkat Nyeri & Jumlah & Prosentase & $\begin{array}{l}\text { Cumulative } \\
\text { prosentase }\end{array}$ \\
\hline Nyeri Berat & 5 & 16,7 & 16,7 \\
\hline Nyeri Sedang & 20 & 66,7 & 83,3 \\
\hline Nyeri Ringan & 5 & 16,7 & 100 \\
\hline Total & 30 & 100 & \\
\hline
\end{tabular}

\section{TABEL 3 \\ Tingkat nyeri pasien kemoterapi \\ di RSUP Dr. Kariadi Semarang sesudah \\ dilakukannya Hypnoterapi}

\begin{tabular}{lccc} 
Tingkat Nyeri & Jumlah & Prosentase & $\begin{array}{c}\text { Cumulative } \\
\text { prosentase }\end{array}$ \\
\hline Nyeri Berat & 1 & 3,3 & 3,3 \\
Nyeri Sedang & 12 & 40,0 & 43,3 \\
Nyeri Ringan & 17 & 56,7 & 100 \\
Total & 30 & 100 & \\
\hline
\end{tabular}

\section{PEMBAHASAN}

Berdasarkan hasil penelitian terhadap karakteristik responden, faktor yang mempengaruhi persepsi nyeri dan kecemasan pada pasien kemoterapi adalah faktor jenis kelamin dan pekerjaaan. Hal ini diperkuat oleh hasil penelitian yaitu responden terbanyak berjenis kelamin perempuan $(83,3 \%)$ dan sebagian besar masih aktif bekerja (60\%). Stuart (2006) menyatakan bahwa gangguan kecemasan lebih sering terjadi pada perempuan dibandingkan pada laki-laki.

Pengalaman responden terhadap tindakan kemoterapi tidak berpengaruh banyak terhadap tingkat kecemasan yang dialaminya, dimana sebagian besar responden sudah menjalani kemo siklus ke 4-6 dari beberapa siklus yang direncanakan. Hal ini berbeda dengan pernyataan Kaplan dan Sadock (1997) bahwa kecemasan yang terjadi pada pasien kemoterapi disebabkan oleh pengalaman awal pasien dalam pengobatan. Pengalaman awal ini sebagai bagian penting dan bahkan sangat menentukan bagi kondisi mental individu di kemudian hari.

Berdasarkan wawancara yang tidak terstruktur yang dilakukan peneliti dengan responden, beberapa responden mengeluhkan nyeri pada tenggorokan, nyeri 


\section{TABEL 4 \\ Tingkat cemas pasien kemoterapi \\ di RSUP Dr. Kariadi Semarang sebelum dilakukannya Hypnoterapi}

\begin{tabular}{lccc} 
Tingkat Cemas & Jumlah & Prosentase & $\begin{array}{c}\text { Cumulative } \\
\text { prosentase }\end{array}$ \\
\hline Cemas Berat & 5 & 16,7 & 16,7 \\
Cemas Sedang & 22 & 73,3 & 90 \\
Cemas Ringan & 3 & 10 & 100 \\
Total & 30 & 100 & \\
\hline
\end{tabular}

\section{TABEL 5}

Tingkat cemas pasien kemoterapi

di RSUP Dr. Kariadi Semarang setelah

dilakukannya Hypnoterapi

\begin{tabular}{lccc} 
Tingkat Cemas & Jumlah & Prosentase & $\begin{array}{c}\text { Cumulative } \\
\text { prosentase }\end{array}$ \\
\hline Cemas Berat & 0 & 0 & 0 \\
Cemas Sedang & 7 & 23,3 & 23,3 \\
Cemas Ringan & 23 & 76,7 & 100 \\
Total & 30 & 100 & \\
\hline
\end{tabular}

\section{TABEL 6}

Hasil Uji statistik Wilcoxon sign rank test untuk nyeri dan hypnoterapi

\begin{tabular}{lcc} 
Test statistik & $\begin{array}{c}\text { Nyeri } \\
\text { sebelum }\end{array}$ & $\begin{array}{c}\text { Nyeri } \\
\text { sesudah }\end{array}$ \\
\hline$Z$ & $-4,455$ \\
Asymp sig (2 tailed) & 0.000 \\
a. Based on negative rank & \\
b. Wilcoxon sign rank test & \\
\hline
\end{tabular}

saat batuk atau nyeri pinggang atau tulang belakang, berdasarkan hasil pemeriksaan penunjang sudah terjadi penyebaran pada daerah tersebut. Sedangkan untuk rasa cemas, sebagian besar responden menyatakan bahwa rasa cemas mereka lebih disebabkan karena efek samping dari pemberian kemoterapi seperti mual, muntah diare dan kurangnya nafsu makan. Kondisi-kondisi inilah yang membuat daya tubuh mereka semakin melemah, sehingga harus melakukan rawat inap beberapa hari untuk perbaikan keadaan umum sebelum masuk kemoterapi selanjutnya. Hal ini sesuai dengan pernyataan dari Gale dan Charrette (2000) bahwa akibat dari dampak yang tidak diinginkan atau dampak yang tidak menguntungkan dari pemberian kemoterapi, pasien akan mengalami gangguan atau kelelahan fisik sehingga akan lebih mudah mengalami stres atau kecemasan. Selain itu, kesehatan umum seseorang seperti kondisi penderita kanker sangat berhubungan nyata sebagai predisposisi terhadap kecemasan (Ibrahim, 2003).

Skala tingkat nyeri pasien kemoterapi sebelum diberikan hypnoterapi rata-rata yaitu 5,1 dengan skala nyeri terbesar yaitu pada angka 9, sesudah dilakukan hypnoterapi skala nyeri rata-rata menjadi 3,5 dengan skala terendah pada angka 1. Dapat dilihat bahwa terjadi penurunan yang signifikan terhadap tingkat nyeri pasien kemoterapi setelah dilakukannya hypnoterapi.

Untuk kecemasan, hasil penelitian menunjukkan skala tingkat kecemasan pasien kemoterapi sebelum diberikan hypnoterapi rata-rata yaitu 61,67 dengan skala kecemasan terbesar yaitu pada angka 90, sesudah dilakukan hypnoterapi skala tingkat kecemasan rata-rata 36,33 dengan skala penurunan sampai dengan angka 20. Dapat dilihat bahwa terjadi penurunan yang signifikan terhadap intensitas kecemasan pasien yang sedang menjalani kemoterapi sesudah dilakukannya hypnoterapi.

Berdasarkan uji hipotesis terdapat pengaruh hipnoterapi terhadap penurunan tingkat nyeri dan kecemasan pada pasien kemoterapi. Hal ini berarti metode hypnoterapi merupakan tindakan non farmakologis yang sangat efektif dilakukan untuk mengurangi rasa nyeri dan kecemasan yang dirasakan oleh pasien yang sedang menjalani kemoterapi. Hypnoterapi menstimulir otak untuk melepaskan neurotransmitter, zat kimia yang terdapat di otak, encephalin dan endorfin yang berfungsi untuk meningkatkan mood sehingga dapat merubah penerimaan individu terhadap sakit atau gejala fisik lainnya, zat ini juga akan membuat seseorang menjadi lebih rileks, sehingga ketegangan otot akan menurun, cemas berkurang (Potter dan Perry, 2006).

Keterbatasan yang ada dalam penelitian ini adalah peneliti hanya melakukan satu kali tindakan hypnoterapi terhadap pasien, sehingga efektifitas sugesti hanya dirasakan oleh pasien saat itu juga setelah dilakukannya hipnoterapi, untuk mendapatkan perubahan perilaku atau efek yang lebih lama hipnoterapi harus dilakukan berulang-ulang. Kesulitan yang dialami peneliti terutama pada tahap pre induksi dan kapan dimulainya tahap hypnotheraupetik pada pasien. Pada tahap pre induksi peneliti harus dapat menggunakan cara yang efektif untuk meyakinkan responden mengenai hypnoterapi, karena sebagian besar pada awalnya merasa takut dengan tindakan hypnosis yang akan dilakukan. 


\section{SIMPULAN}

Tingkat nyeri dan kecemasan pasien yang sedang menjalani kemoterapi lebih cenderung pada tingkat sedang dan berat, hanya sebagian kecil pasien yang mengalami nyeri ringan dan cemas ringan. Hal ini dimungkinkan karena pasien dengan kanker akan mengalami nyeri kronik dan kecemasan yang menetap berhubungan dengan rangkaian program tindakan yang akan dilakukan.

Beberapa faktor yang mempengaruhi tingkat nyeri dan kecemasan pasien yang sedang menjalani kemoterapi berasal dari faktor internal dan eksternal. Faktor-faktor tersebut antara lain adalah jenis kelamin, jenis pekerjaan pasien, tindakan kemoterapi dan efek sampingnya serta komplikasi dari kanker itu sendiri.

Metode Hypnoterapi merupakan tindakan non farmakologis yang sangat efektif dilakukan untuk mengurangi rasa nyeri dan kecemasan yang dirasakan oleh pasien yang sedang menjalani kemoterapi. Hypnoterapi dapat dikembangkan sebagai metode perawatan paliatif pada pasien kondisi terminal.

\section{DAFTAR PUSTAKA}

1. Ibrahim, AS . Panik Neurosis dan Gangguan Cemas.Jakarta: Dua As-As. Jakarta; 2003

2. Dahlan, Sopiyudin. Statistic Untuk Kedokteran dan Kesehatan. Jakarta: Salemba Medika; 2000

3. Gale, D \& Charette J. Rencana Asuhan Keperawatan Onkologi, alih bahasa I Made Kasiasa. Jakarta: EGC ; 2000

4. Gayatri, D . Peluang Ketahanan Hidup 5 Tahun Pasien Kanker Serviks di RSUPN Dr. Cipto Mangunkusumo \& RSK Dharmais, Jurnal Keperawatan Indonesia : 2003

5. Hakim, A . Hypnotherapi cara Cepat dan Tepat mengatasi Stress, Fobia, Trauma dan Gangguan Mental Lainnya. Jakarta: Transmedia Pustaka; 2010

6. HipnoterapisKlinis/Medis, http://sites.google.com/ site/untunghypnotherapy

7. Kaplan J.B \& Saddock T.C Sinopsis Psikiatri ; Ilmu Pengetahuan Perilaku dan Psikiatri Klinis. Edisi ketujuh. Jakarta: Binapura Aksara;1997

8. Khoirul Umam . Efektifitas Hipnoterapi terhadap Penurunan Intensitas Nyeri pada Pasien Pasca Operasi Bedah Mayor Abdomen di RSUP DR Kariadi Semarang. Skripsi. Semarang: Universitas Muhammadiyah Semarang. Tidak dipublikasikan.2012

9. Long B.C. Perawatan Medikal Bedah; suatu Pedoman Proses Keperawatan 2. Bandung: Yayasan IAPK;1996

10. Mc Closkey, C.Joanne and Bulecheck. Nursing Interventions Classification (NIC). Third edition. United State of America: Mosby,Inc;2003

11. Nurachmah, E. Dampak Kanker Payudara dan Pengobatannya terhadap Aspek Bio-Psiko-Sosio-Spiritual Klien yang Berpartisipasi dalam Kelompok Pendukung. Jurnal Keperawatan Indonesia Vol II. Jakarta: Universitas Indonesia; 1999

12. Potter \& Perry . Fundamental Keperawatan: Konsep, Proses dan Praktik, (Edisi 4). Jakarta:EGC; 2006

13. Nursalam. Konsep \& Penerapan Metodologi Penelitian Ilmu Keperawatan; Pedoman skripsi, tesis dan Instrumen Keperawatan. Jakarta: Salemba Medika; 2003 